ACORDOS

\title{
ANTICONCORRENCIAIS \\ E A REGRA DA RAZÃO \\ ESTRUTURADA NO DIREITO \\ DA UNIÃO EUROPEIA
}

\author{
Anti-competitive agreements and the structured \\ rule of reason in European Union Law
}

Pablo Leurquin ${ }^{1}$

\section{RESUMO}

O presente artigo tem como objetivo apresentar a metodologia de aplicação da regra da razão estruturada no eixo dos acordos do Direito da Concorrência da União Europeia. A abordagem proposta se ancora na interpretação dada, pela doutrina e pelos tribunais, aos tratados, regulamentos e orientações da Comissão Europeia que versam sobre o assunto. 0 processo de modernização desse ramo do Direito, bem como da própria tradição do Direito da União Europeia, são os pontos de partida para a compreensão das principais peculiaridades da regra da razão estruturada. 0 artigo foi, portanto, dividido em três seções. A primeira aborda alguns aspectos da modernização do eixo dos acordos anticoncorrenciais. A segunda trata da etapa da qualificação do acordo, conforme disposto no art. 101, parágrafo 1으, do Tratado de Funcionamento da União Europeia. A terceira versa sobre as isenções, no sentido do art. 101, parágrafo 3ㅇ, do mesmo tratado. Foi possivel constatar que o modelo modernizado da regra da razão estruturada na União Europeia apresenta diferenças substanciais se comparado à regra da razão (rule of reason) estadunidense.

Palavras-chave: Direito da União Europeia; Direito da Concorrência; Direito Econômico; Acordos anticoncorrenciais; Regra da razão estruturada

\begin{abstract}
The purpose of this article is to present the methodology for the application of the structured rule of reason in the framework of the agreements in European Union competition law. The proposed approach is anchored in the interpretation given by doctrine and by the courts to treaties, regulations and guidelines of the European Commission that deal with the subject. The modernization process of

1 Doutor em Direito pela Université Paris 1 Panthéon-Sorbonne e pela Universidade Federal de Minas Gerais, em cotutela. Mestre em Direito pela Universidade Federal de Minas Gerais. Bacharel em Direito pela Universidade Federal do Rio Grande do Norte. Professor Adjunto da Universidade Federal de Juiz de Fora - campus Governador Valadares. Líder do Centro de Pesquisa em Direito Econômico (CPDE-UFJF/GV) e do Centro de Estudos em Pensamento Político (CEPP-UFJF/GV). E-mail: pabloleurquin@gmail.com
\end{abstract}


this branch of law, as well as of the European Union law tradition itself, are the starting points for understanding the main peculiarities of the structured rule of reason. The article is therefore divided into three sections. The first addresses some aspects of the modernization of the framework of anti-competitive agreements. The second deals with the stage of qualification of the agreement, as provided in article 101(1), of the Treaty on the Functioning of the European Union. The third deals with exemptions, in the sense of article 101(3), of the same treaty. It was possible to verify that the modernized model of the structured rule of reason in the European Union presents substantial differences when compared to the American rule of reason.

Keywords: European Union Law. Competition Law. Economic Law. Anti-competitive agreements. Structured rule of reason.

\section{Classificação: K21}

Sumário: 1. Introdução; 2. Aspectos gerais da modernização do eixo dos acordos anticoncorrenciais; 3. Qualificação de acordo no Direito da Concorrência da União Europeia; 3.1. Conceito jurídico de colusão; 3.2. Definição da restrição de concorrência; 4. Ponderação no sentido do art. 101, parágrafo 3o, TFUE; 4.1. Isenção por categoria; 4.2. Isenção individual; 5. Conclusão.

\section{INTRODUÇÃO}

A integridade do mercado interno europeu é um dos valores fundamentais da construção do mercado comum europeu. O Tratado sobre Funcionamento da União Europeia (TFUE), em seu art. 26, 2o- dispõe que o mercado interno é “um espaço sem fronteiras internas no qual a livre circulação de mercadorias, das pessoas, dos serviços e dos capitais é assegurada de acordo com as disposições dos Tratados". No seu art. 26, 1o, fica estabelecido também que é de competência da União Europeia adotar medidas para estabelecer e assegurar o funcionamento do seu mercado interno. 0 art. 101 e seguintes do TFUE, por sua vez, estabelecem os parâmetros de compatibilidade dos atos das empresas com o próprio mercado interno (LEURQUIN, 2018, p. 28).

O referido tratamento jurídico do mercado interno se soma a uma interpretação instrumental da aplicação do Direito da Concorrência. Laurence Idot afirma que o modelo da União Europeia não estabelece a defesa da concorrência como um fim em si mesmo, ou seja, ela é voltada à implementação de políticas públicas, de maneira a viabilizar a avaliação de considerações de interesse geral (IDOT, 2012, p. 10).

O Direito da Concorrência da União Europeia passou por processos de modernização com intuito de promover uma adequação da tradicional forma de aplicar este ramo do Direito às novas exigências da economia contemporânea. Constatou-se, assim, a incorporação de aportes da Economia Industrial nos tradicionais quadros de análise consolidados pelas autoridades europeias. A referida modernização ocorreu nos dois eixos do Direito Europeu da Concorrência, a saber, o de acordos anticoncorrenciais, com o regulamento n. 1/2003; e o de práticas unilaterais, com as Orientações sobre as prioridades da Comissão na aplicação do art. 82 (atual art. 102), do TFUE.

É importante frisar uma diferença entre as duas fontes de Direito Europeu: as orientações da Comissão Europeia e os regulamentos europeus. As primeiras são consideradas normas de soft law (droit mou), cujo objetivo é vincular a atuação da própria Comissão Europeia para garantir maior 
previsibilidade jurídica. Essas orientações não vinculam a interpretação das jurisdições nem das autoridades dos Estados membros. Já os regulamentos, de acordo com o art. 288 do Tratado sobre o Funcionamento da União Europeia, têm caráter geral e são diretamente aplicáveis e obrigatórios em todos os Estados-Membros (UNIÃO EUROPEIA, 2012; JACQUÉ, 2015, p. 572).

As distinções entre as duas técnicas legislativas empregadas para consolidar a modernização do Direito da Concorrência da União Europeia dão pistas sobre os desafios de aplicação dos diferentes eixos deste ramo do Direito. Mas essa reflexão sobre fontes do Direito da União Europeia não será aprofundada no presente trabalho. 0 objetivo deste artigo é refletir sobre a regra da razão estruturada no controle de concentrações, a partir dos contornos firmados pelo processo de modernização mencionado. Trata-se, portanto, de um trabalho de dogmática jurídica e tem como pretensão apresentar os aspectos introdutórios da aplicação do Direito da Concorrência da União Europeia no campo dos acordos anticoncorrenciais. Para tanto, será realizada uma exposição dos pormenores da metodologia da aplicação do art. 101, TFUE, que é disposta no próprio artigo e nas Orientações da Comissão concernentes à aplicação do art. 101.

O artigo será dividido em três seções. A primeira abordará sucintamente alguns aspectos gerais sobre a modernização do eixo dos acordos anticoncorrenciais. A segunda tratará da etapa da qualificação de acordo, conforme disposto no art. 101, parágrafo 1ọ, do TFUE. A terceira versará sobre a etapa da avaliação das isenções, no sentido do art. 101, parágrafo 3o, TFUE.

\section{ASPECTOS GERAIS DA MODERNIZAÇÃO DO EIXO DOS ACORDOS AN- TICONCORRENCIAIS}

A regra da razão estruturada decorre do encontro entre a tradição europeia e a nova abordagem fundada nos efeitos. Em síntese, promoveu-se uma original convergência entre a tradição administrativista de origem dos países de tradição civilista, expressa por uma concepção aproximada às proibições per se, e a análise de caso a caso, típicas de países mais influenciados pela common law. O modelo da União Europeia da regra da razão estruturada é ancorado igualmente na busca por técnicas mais realistas de análise econômica, notadamente no que diz respeito à incorporação dos novos aportes da Economia Industrial.

As origens da Economia Industrial remontam as contribuições de Antoine Augustin Cournot e Jules Dupuit, que foram em seguida desenvolvidas, no campo do Direito da Concorrência, pela aplicação do Sherman Act e legislações subsequentes. Essa teoria influenciou sobremaneira o Antitrust Law estadunidense até a ascensão e hegemonia da Escola de Chicago. Com a crise de 2008, o Movimento Pós-Chicago incorporou reflexões da Nova Economia Industrial no Direito da Concorrência². Um dos principais representantes desta teoria é Jean Tirole, economista francês e membro da Escola de Economia de Toulouse (TIROLE, 2014 e 2016; SALOP; SHAPIRO, 2015). Além das suas contribuições no fortalecimento do potencial analítico da Nova Economia Industrial, o economista influenciou a própria modernização do Direito da Concorrência da União Europeia (LEURQUIN, 2018, p. 282).

A modernização do Direito da Concorrência da União Europeia, no tocante ao controle de

2 Para uma síntese da evolução da aplicação dos preceitos da Corrente Pós-Chicago nos EUA, ver: HOVENKAMP, 2010; DAUDRET-JOHN; SOUTY, 2009; e POLI, 2015. 
acordos anticoncorrenciais, culminou no Regulamento n. 1/2003 (CONSELHO DA UNIÃO EUROPEIA, 2003). Esta norma foi responsável por importantes alterações na política europeia de concorrência, na busca por adequar a defesa da concorrência ao fenômeno da intensificação da globalização e ao aumento da quantidade de países membros da União Europeia.

A desconcentração da aplicação das normas de Direito da Concorrência é uma das principais mudanças, pois a sua implementação passou a ser de competência das autoridades nacionais da concorrência (ANC) e não apenas da Comissão Europeia. Essa alteração permitiu o fortalecimento da cooperação entre os membros da rede de autoridades da concorrência (REC), composta pelas ANC e Comissão Europeia (COMISSÃO EUROPEIA, 2004). Outra alteração trazida pelo Regulamento n. 1/2003 foi a implementação da desnecessidade de notificação prévia dos acordos (art. 1ำ, do parágrafo 2o-).

A Comissão Europeia elaborou, em 2004, as orientações sobre a aplicação do art. 81 (atual art. 101), parágrafo 3o, e deu sequência à modernização da aplicação das regras concorrenciais em matéria de acordos. A primeira contribuição dessas orientações foi organizar claramente a jurisprudência sobre o assunto, o que permitiu a formulação de um quadro geral de análise e de conceitos. A segunda contribuição foi elucidar a aproximação fundada nos efeitos, com base na incorporação das evoluções teóricas da Nova Economia Industrial. Ou seja, a Comissão Europeia sistematizou o que se entende por ganhos de eficiência, tanto na qualificação de restrição de concorrência, quanto na ponderação dos efeitos positivos das operações. O diálogo entre os regulamentos de isenção e os documentos de soft law é uma outra característica importante no domínio dos acordos no Direito da Concorrência da União Europeia, garantindo a segurança jurídica dos contratos e dos consumidores.

\section{QUALIFICAÇÃO DE ACORDO NO DIREITO DA CONCORRÊNCIA DA UNIÃO EUROPEIA}

A qualificação de acordo é a primeira etapa da metodologia geral da aplicação do Direito da Concorrência da União Europeia no eixo dos acordos anticoncorrenciais. 0 art. 101, do parágrafo 1으, do TFUE, dispõe:

São incompativeis com o mercado interno e proibidos todos os acordos entre empresas, todas as decisões de associações de empresas e todas as práticas concertadas que sejam susceptiveis de afectar o comércio entre os Estados-Membros e que tenham por objectivo ou efeito impedir, restringir ou falsear a concorrência no mercado interno (UNIÃO EUROPEIA, 2012).

Esse texto pode ser dividido em duas partes. A primeira faz a identificação de que tipo de ato pode incidir a aplicação desse artigo, podendo implicar "acordos entre empresas", "decisões de associações de empresas" e "todas as práticas concertadas". Esses três conceitos têm em comum a noção de colusão, que precisa ser caracterizada para a incidência do art. 101. O conceito de colusão, por vezes, é tratado como sinônimo de restrição de concorrência. Apesar disso, a jurisprudência europeia compreende que são dois elementos independentes e necessários para a qualificação da nocividade do acordo.

Já a segunda parte do texto do art. 101, parágrafo 1ọ, é destinada a adjetivar essa prática, uma vez que esta deve "afetar o comércio entre os Estados-Membros", cujo “objetivo ou efeito" possa “im- 
pedir, restringir ou falsear a concorrência no mercado interno". Em outras palavras, deve-se constatar a restrição da concorrência.

\subsection{Conceito jurídico de colusão}

A colusão é o antônimo da autonomia de comportamento, um dos fundamentos teóricos da economia de mercado, visto que a coordenação de comportamentos não só impede a formação de um preço ideal, mas também atenta à diversidade na oferta e à inovação (PRIETO; BOSCO, 2013, p. 434). Na aplicação do Direito da Concorrência da União Europeia, a sua constatação tem como escopo distinguir a defesa da concorrência no eixo dos acordos entre empresas (art. 101, TFUE) da aplicação dessas normas jurídicas no eixo dos comportamentos unilaterais (art. 102, TFUE). Em outros termos, trata-se de uma etapa fundamental na metodologia da aplicação do art. 101, mas não faz parte daquela do art. 102.

As Orientações da Comissão relativas à aplicação do art. 101 estabelecem que tipo de coordenação dos comportamentos ou de colusão o referido artigo faz referência. De acordo com as mesmas:

[...] é aquele em que pelo menos uma empresa se comprometa perante outra a adoptar determinada conduta no mercado ou que, na sequência de contactos entre elas, seja eliminada ou, pelo menos, substancialmente reduzida, a incerteza quanto à sua conduta no mercado (COMISSÃO EUROPEIA, 2020, §15).

Esse conceito trazido pela Comissão remonta o acórdão Imperial Chemical Industrie, de 1972. Ele foi responsável por iniciar um corpo jurisprudencial no Direito da União Europeia que declara ilegal a cooperação de um produtor com seus concorrentes para determinar estratégias coordenadas no mercado (TRIBUNAL DE JUSTIÇA DAS COMUNIDADES EUROPEIAS, 1972, §118).

O art. 101 do TFUE estabelece três formas de coordenação: acordos entre empresas, decisão de associação de empresas e práticas concertadas. As autoridades de defesa da concorrência da União Europeia entendem que as três categorias são noções autônomas e têm peculiaridades que devem ser explicadas.

O acordo, no sentido do art. 101, do TFUE, é a expressão da vontade comum das empresas de se comportar sob o mercado de maneira determinada. A noção de acordo se aplica também aos casos em que o contrato é nulo ou ineficaz, desde que a cláusula controvertida exprima a vontade das partes (TRIBUNAL DE JUSTIÇA DAS COMUNIDADES EUROPEIAS, 1990). Portanto, a discussão sobre os vícios de consentimento não é empregada nesse caso. Além disso, os efeitos do acordo podem se prologar após a cessação formal do fim do contrato.

A decisão de associação se manifesta sob as formas institucionalizadas de cooperação, nas quais os operadores econômicos agem por intermédio de uma estrutura coletiva ou de um órgão 
comum ${ }^{3}$. Faz-se necessária a constatação da comunidade de interesses ou de um interesse comum para caracterizar a existência de uma associação, já que a construção jurisprudencial sustenta a importância de compreender essa noção em função de sua finalidade e em um sentido mais abrangente. Portanto, verifica-se que não se deve dar grande importância ao regime jurídico da decisão de associação, pois a sua qualificação depende apenas de seu objeto. Isso quer dizer que a associação pode-se manifestar sob a forma de uma associação sem fins lucrativos (TRIBUNAL DE JUSTIÇA DAS COMUNIDADES EUROPEIAS, 1980, §86), de uma associação de fato ${ }^{4}$, de uma federação, de um agrupamento de interesses econômico e de toda a forma de agrupamento público ou privado de empresas com objetivos de captar uma clientela, de promover uma categoria de produto ou de vender.

A prática concertada, por sua vez, é o comportamento decorrente de uma coordenação entre as empresas com uma relação de causa e efeito sob o mercado. As diferenças entre o acordo, em face da prática concertação, são a intensidade e as formas de manifestação do concurso de vontade, uma vez que a prática concertada não reúne todos os elementos de um acordo. Constada a colusão em uma dessas três categorias, o próximo passo é definir a restrição de concorrência.

\subsection{Definição da restrição de concorrência}

A identificação da restrição de concorrência é uma etapa central da análise das autoridades responsáveis pela concorrência, notadamente após a modernização mencionada, com a incorporação de uma abordagem mais econômica. A Comissão Europeia se ancorou na jurisprudência do Tribunal de Justiça e procurou apresentar uma exposição metodológica para caracterizar a restrição de concorrência. Seu objetivo foi vincular a sua própria prática, para respeitar a previsibilidade jurídica. Entretanto, importa frisar que esta norma não vincula a interpretação das jurisdições e das autoridades dos Estados-Membros (COMISSÃO EUROPEIA, 2004, 2020, §4 e 7). É igualmente importante destacar que o diálogo entre a Comissão e o Tribunal de Justiça promoveu uma convergência entre as exigências de cada instituição, o que é essencial para entender o fortalecimento da política europeia de concorrência.

As orientações retomam o texto do art. 101, do TFUE, que estabelece duas maneiras de caracterizar a restrição de concorrência, por objeto ou por efeitos. Existe uma sutil distinção entre esses dois conceitos. Em síntese, o Direito da Concorrência da União Europeia descarta a necessidade de comprovação dos efeitos anticoncorrenciais concretos do ato no caso se a restrição por objeto for devidamente comprovada. Ou seja, se faz obrigatória a análise da restrição por efeitos apenas no caso de a restrição por objeto não ser qualificada. Assim, a autonomia da restrição por objeto é uma importante construção europeia que facilita a aplicação do art. 101, do parágrafo 1o.

É comum afirmar que o Direito da Concorrência da União Europeia é aplicado de maneira

3 A condenação da MasterCard, por exemplo, se ancorou na caracterização do interesse comum dos bancos pelo sistema de fixação de comissões interbancárias supletivas. Ficou constatado que essa estratégia permitia a definição de um preço mínimo da prestação do serviço, que acabava por repercutir sobre os comerciantes (TRIBUNAL DE JUSTIÇA DA UNIÃO EUROPEIA, 2012, § 243 e 251).

$4 \quad$ No caso Erste Group Bank et al. x Comissão, houve a condenação de bancos austríacos que fixavam as taxas de juros das operações passivas e ativas sob a organização do "Clube Lombard" (TRIBUNAL DE JUSTIÇA DAS COMUNIDADES EUROPEIAS, 2009). 
muito rígida e excessivamente formal. Por essa razão, o principal desafio dos juristas europeus foi modernizar esse ramo do Direito sem perder de vista a sua tradição legalista-administrativista. Em outras palavras, buscou-se promover uma interpretação mais realista do mercado, sem deixar de lado o caráter jurídico e formal da atuação dos órgãos europeus.

A análise in concreto é um ponto em comum essencial e comum às duas categorias de qualificação. Essa análise remonta à decisão Société Technique Minière, de 1966 (TRIBUNAL DE JUSTIÇA DAS COMUNIDADES EUROPEIAS,1966), e continua a ser, ainda hoje, um eixo importante na metodologia geral. Este caso teve como objeto a formulação de questões prejudiciais ao Tribunal de Justiça das Comunidades Europeias sobre a interpretação do direito exclusivo de venda e a abrangência da nulidade prevista no então art. 85 n. 2 do Tratado de Roma. Importa destacar que o Tribunal de Justiça das Comunidades Europeias afirmou que: “A proibição do acordo depende apenas da questão de saber se, ponderadas as circunstâncias do caso concreto, tal acordo reúne objectivamente os elementos constitutivos da referida proibição, tal como vêm enunciados no $n^{\circ} 1$ do artigo $85^{\circ}$ ". Assim, a estrutura de mercado, o conteúdo do acordo, seus objetivos e a natureza dos bens e serviços são, desde 1966, elementos presentes na apreciação da restrição da concorrência de maneira indiferenciada. Este entendimento, entretanto, pode dificultar a percepção dicotômica da caracterização pelo objeto e pelo efeito.

É fundamental retomar o texto do art. 101, do parágrafo 1o, do TFUE, para dar início à conceituação da restrição por objeto. Esse dispositivo legal dispõe que os acordos não serão compativeis com o mercado comum quando eles visam a:

a) Fixar, de forma directa ou indirecta, os preços de compra ou de venda, ou quaisquer outras condições de transacção;

b) Limitar ou controlar a produção, a distribuição, o desenvolvimento técnico ou os investimentos;

c) Repartir os mercados ou as fontes de abastecimento;

d) Aplicar, relativamente a parceiros comerciais, condições desiguais no caso de prestações equivalentes colocando-os, por esse facto, em desvantagem na concorrência;

e) Subordinar a celebração de contratos à aceitação, por parte dos outros contraentes, de prestações suplementares que, pela sua natureza ou de acordo com os usos comerciais, não têm ligação com o objecto desses contratos (UNIÃO EUROPEIA, 2012).

A Comissão Europeia estabeleceu que os acordos têm por objeto a restrição do jogo da concorrência quando eles são muito suscetíveis a ter efeitos negativos, de maneira a prejudicar os princípios do Direito da Concorrência. Os exemplos utilizados nas comunicações são a partilha do mercado e a fixação dos preços, já que reduzem a produção e aumentam os preços. De acordo com a Comissão Europeia, essas circunstâncias diminuem o bem-estar dos consumidores devido à má alocação dos recursos (COMISSÃO EUROPEIA, 2004, §21).

A jurisprudência do Tribunal de Justiça da União Europeia (TJUE), por sua vez, permite acres- 
centar certos outros casos de nocividade, como o fechamento dos mercados nacionais e o entrave ao comércio paralelo, a repartição dos mercados e a troca de informações constitutivas de práticas concertadas. O TJUE estabeleceu um quadro de análise para avaliar a restrição por objeto. De acordo com o mesmo, faz-se necessário analisar os objetivos do acordo, seu contexto econômico e jurídico, a natureza dos bens e serviços, as condições reais do funcionamento e a estrutura do mercado.

No que diz respeito à nocividade dos acordos, é importante ressaltar que a Comissão Europeia indica que as restrições caracterizadas são normalmente restrições por objeto (COMISSÃO EUROPEIA, 2004, §23). As restrições caracterizadas são eventuais efeitos negativos, em termos concorrenciais, que estão dispostas nos regulamentos de isenção. A Comissão Europeia menciona também algumas outras situações, de maneira não exaustiva, que devem ser compreendidas como restrições pelo objeto. O TJUE, no entanto, colocou em prática uma análise sobre a existência de restrição de concorrência diferente da Comissão, especificamente na decisão Pierre Fabre (TRIBUNAL DE JUSTIÇA DA UNIÃO EUROPEIA, 2011).

Em sintese, de acordo com a Comissão Europeia, a caracterização da restrição por objeto descarta a necessidade da utilização da técnica de restrição pelos efeitos. O TJUE compreendeu de maneira diversa, e sustentou que se faz necessário reconstituir a análise da qualificação pelo efeito ainda na avaliação da restrição por objeto. Entende-se, todavia, de acordo com Laurence Idor, que o mais coerente é "admitir desde o início que as restrições caracterizadas são restrições de concorrência pelo objeto, o que não exclui que elas sejam eventualmente justificadas em um segundo momento, na perspectiva do parágrafo 3 (IDOT, 2012, p. 18).

A sequência da metodologia de aplicação do art. 101, quando não há restrição por objeto, é analisar se há a qualificação pelos efeitos. Ou seja, a técnica de restrição pelos efeitos é subsidiária e tem grande relevância no que diz respeito à nova aproximação fundada nos efeitos do Direito da Concorrência da União Europeia. Nessa hipótese, o órgão responsável pela concorrência deve explicitar os efeitos nocivos à concorrência da prática em análise. Ela deve respeitar a definição do poder de mercado, a verificação de uma restrição significativa e a comparação com a situação contrafactual.

O poder de mercado é definido pela Comunicação da Comissão sobre a aplicação do art. 81 como:

[...] a capacidade de manter os preços acima dos niveis concorrenciais durante um período de tempo significativo ou de manter a produção, em termos de quantidade, qualidade e variedade do produto ou inovação, abaixo dos niveis concorrenciais durante um período de tempo significativo (COMISSÃO EUROPEIA, 2004, § 25)

Para mensurar o poder de mercado, é necessário definir o mercado relevante, a natureza dos produtos, a posição do mercado das partes, dos concorrentes e dos compradores, bem como a existência de concorrentes potenciais e do nível de barreiras à entrada. A restrição pelo efeito será caracterizada quando o acordo deve afetar a concorrência real ou potencial, de maneira a identificar a probabilidade dos efeitos negativos no mercado relevante no nível dos preços, produção, inovação 
e variedade ou qualidade dos bens e serviços 5 . Essa possibilidade de analisar os desdobramentos potenciais recoloca em discussão a aplicação das práticas anticoncorrenciais no tempo. Isso altera a compreensão clássica de que o controle dessa dimensão do Direito da Concorrência é realizado exclusivamente a posteriori.

A verificação do efeito sensivel é essencial para a qualificação por efeito. A Comissão Europeia apresenta alguns critérios úteis sobre a questão na Comunicação relativa aos acordos de pequena importância que não restringem sensivelmente a concorrência nos termos do artigo 101, n. 1 (Comunicação de minimis), a qual estabelece que:

A Comissão considera que os acordos entre empresas que podem afetar o comércio entre os Estados-Membros e que podem ter por efeito impedir, restringir ou falsear a concorrência no mercado interno não restringem sensivelmente a concorrência na aceção do artigo 101, n. 1, do Tratado: a) Se a quota de mercado agregada das partes no acordo não ultrapassar $10 \%$ em qualquer dos mercados relevantes afetados pelo acordo, quando o acordo for concluido entre empresas que sejam concorrentes efetivos ou potenciais em qualquer desses mercados (acordos entre concorrentes); ou b) Se a quota de mercado de cada uma das partes no acordo não ultrapassar $15 \%$ em qualquer dos mercados relevantes afetados pelo acordo, quando este for concluído entre empresas que não sejam concorrentes efetivos nem potenciais em qualquer desses mercados (acordos entre não concorrentes) (COMISSÃO EUROPEIA, 2014,§ 8).

Esses limites de partes de mercado servem para constatar a ausência de efeito sensivel da restrição da concorrência. Isto significa que não se aplica a análise de restrição por efeito nos casos cujas participações de mercado são inferiores às de $10 \%$, no caso de concorrentes, e de $15 \%$, quando não forem concorrentes.

A análise da situação contrafactual (counterfactual test) também tem papel importante na apreciação dos efeitos anticoncorrenciais, sobretudo no exame do contexto do acordo. A Comissão entende que "ao determinar se um acordo restringe a concorrência deve ter-se em conta o contexto em que a concorrência se processaria efectivamente na ausência do acordo com as suas alegadas restrições" (COMISSÃO EUROPEIA, 2004, § 17). A expressão "comparação com a situação contrafactual" é a tradução de "comparaison avec la situation contrefactuelle", que remete ao conceito "contrafactual test", de origem anglo-saxônica. Na ótica de Catherine Prieto e David Bosco, a "apreciação de uma restrição da concorrência repousa então sob uma comparação entre a situação existente e a situação que poderia ter advindo" (PRIETO; BOSCO, 2013, p. 479).

Após qualificar o acordo e definir se este restringe a concorrência por objeto ou por efeitos, a próxima etapa da metodologia está disposta no art. 101, no parágrafo 3‥ Este dispositivo estabelece os critérios que afastam a ilicitude definida a partir da aplicação do parágrafo 1o do mesmo artigo.

5 Sobre as questões teóricas da relação entre concorrência e inovação, ver: POSSAS, 2013; WU, 2012; RUIZ, 2011. Sobre oS aspectos europeus acerca da aplicação do Direito da Concorrência para a promoção da inovação, ver: VESTAGER, 2017, 2016a e 2016b; LEBLOND, 2014; e GSTALTER, 2012. 


\section{PONDERAÇÃO NO SENTIDO DO ART. 101, PARÁGRAFO 3', TFUE}

A ponderação no sentido do art. 101, no parágrafo 3o é uma das originalidades do Direito da Concorrência da União Europeia ao se comparar com a tradição norte-americana. A "rule of reason" estadunidense é a ponderação dos efeitos econômicos positivos e negativos da prática para estabelecer a licitude, ou não, de determinada prática. A regra da razão foi aplicada desde os primeiros anos da aplicação da Seção 1 do Sherman Act, notadamente com a técnica ancillary restraints. Mas foi apenas com o caso Standard Oil em que as possibilidades desse tipo de ponderação foram aprofundadas. Conforme assinalam Catherine Prieto e David Bosco, o Antitrust Law, ao longo do século XX, é marcado por diferentes temperamentos e alterações no conteúdo da aplicação da regra da razão (rule of reason). Esse conceito continua no centro das discussões sobre a modernização do direito norte-americano, que realiza grandes esforços para fixar seus parâmetros (PRIETO; BOSCO, 2013, p. 525).

A jurisprudência europeia, a partir do caso Grundig-Consten, em 1966, afastou a possibilidade de aplicação da regra da razão do direito norte-americano no Direito da União Europeia. 0 caso em questão tratava da análise concorrencial de um acordo que estabelecia proteção territorial absoluta na distribuição da marca Grunding a favor da empresa Consten, na França. O tribunal teve que se manifestar sobre recurso apresentado pelo governo alemão, pela Grundig-Verkaufs-GmbH e pelos Établissements Consten SARL, que versava sobre vários aspectos. Entre os pleitos, eles questionavam a forma que a metodologia foi adotada pela Comissão Europeia para a aplicação das sanções. O argumento era que a Comissão Europeia deveria realizar previamente uma análise das eficiências do contrato, inspirando-se no rule of reason do Direito norte-americano. Entretanto, de acordo com o Tribunal de Justiça:

\section{[...] para efeitos da aplicação do artigo $85^{\circ}, n .^{\circ} 1$, a tomada em consideração dos efeitos concretos de um acordo é supérflua, desde que seja evidente que tem por objecto restringir, impedir ou falsear a concorrência.}

Portanto, a ausência, na decisão recorrida, de qualquer análise dos efeitos do acordo no plano da concorrência entre produtos similares de diferentes marcas não pode constituir, por si só, um vício da decisão (TRIBUNAL DE JUSTIÇA DAS COMUNIDADES EUROPEIAS, 1966).

A decisão Grundig-Consten inaugurou uma construção jurisprudencial que afasta a aplicação da rule of law norte-americano no Direito Europeu. Essa sentença permitiu a condenação de práticas consideradas graves, sem a análise de eventuais eficiências ao mercado, como é o caso da repartição de mercados nacionais por meio de contratos de exclusividade de distribuição. Decisões seguintes reiteram o julgado mencionado, como é o caso Montecatini, de 19996, mas também da decisão M6, de 2001. Esta última refutou o argumento das partes que sustentavam a existência de um "rule of reason" no Direito Comunitário da Concorrência (Direito da União Europeia). O tribunal reconheceu que

6 De acordo com o Tribunal de Justiça: “[...] mesmo admitindo que a «rule of reason» tenha o seu lugar no âmbito do artigo $81 .^{\circ}$, n. ${ }^{\circ} 1, \mathrm{CE}$, não pode de forma alguma obstar à aplicação dessa disposição no caso de um acordo que implica para os produtores que detinham a quase totalidade do mercado comunitário e que respeita a objectivos de preços, a limitação da produção e a repartição do mercado. Assim, o Tribunal de Primeira Instância não cometeu qualquer erro de direito ao considerar que o carácter óbvio da infracção se opunha, de qualquer modo, à aplicação da «rule of reason»" (TRIBUNAL DE JUSTIÇA DAS COMUNIDADES EUROPEIAS, 1999, § 133). 
algumas decisões da União Europeia permitiram maior flexibilidade às vedações ex ante de diversas condutas. Entretanto, isso não consagrou a utilização da técnica norte-americana. De acordo com o julgado:

[...] estes acórdãos não podem ser interpretados como consagrando a existência de uma "rule of reason" em direito comunitário da concorrência. Inscrevem-se antes numa corrente jurisprudencial mais ampla, segundo a qual não há que considerar, de modo completamente abstracto e indistinto, que todo e qualquer acordo que restrinja a liberdade de acção das partes ou de uma delas cai necessariamente no âmbito da proibição fixada no artigo $85^{\circ}$, n. ${ }^{\circ}$, do Tratado. Com efeito, é necessário, para efeitos de análise da aplicabilidade desta disposição a um acordo, ter em conta o quadro concreto em que produz os seus efeitos, nomeadamente o contexto económico e jurídico em que operam as empresas em causa, a natureza dos produtos e/ou serviços visados por esse acordo e as condições reais do funcionamento e da estrutura do mercado (TRIBUNAL DE PRIMEIRA INSTÂNCIA DAS COMUNIDADES EUROPEIAS, 2001, § 73 a 77 ).

Essas decisões permitem excluir qualquer possibilidade de interpretar as normas europeias com base na experiência norte-americana. A perspectiva modernizada do Direito da União Europeia, denominada de "regra da razão estruturada" ou "regra dos efeitos estruturada", acolheu as lições dos inconvenientes devido à proibição absoluta, sem perder de vista a importância de uma análise jurídico-formal. É importante constatar que as proibições dogmáticas dos acordos não eram coerentes com a dinâmica do mercado contemporânea. Essa percepção decorre de uma parte da experiência estadunidense da regra da razão (rule of reason), no entanto, o modelo da União Europeia não se confunde com ela.

De acordo com o art. 101, do parágrafo 3ํ., TFUE, serão declaradas inaplicadas as disposições do art. 101, do parágrafo 1ำ, a todos os acordos, decisões ou práticas:

[...] que contribuam para melhorar a produção ou a distribuição dos produtos ou para promover o progresso técnico ou económico, contanto que aos utilizadores se reserve uma parte equitativa do lucro dai resultante, e que:

a) Não imponham às empresas em causa quaisquer restrições que não sejam indispensáveis à consecução desses objectivos;

b) Nem dêem a essas empresas a possibilidade de eliminar a concorrência relativamente a uma parte substancial dos produtos em causa (UNIÃO EUROPEIA, 2012).

Esses são os critérios dispostos no TFUE para que determinado acordo não seja considerado ilícito. Outra peculiaridade do Direito da Concorrência da União Europeia decorre do trecho "contribuam para melhorar a produção ou a distribuição dos produtos ou para promover o progresso técnico ou económico". Este excerto do artigo instaura uma avaliação das eficiências geradas pelos acordos, as quais devem ser balizadas pela técnica das isenções, que são de duas naturezas: por categoria ou individual. Essas duas modalidades são uma derrogação da proibição do art. 101, garan- 
tindo uma apreciação formal, mas ancorando-se numa aproximação menos dogmática.

\subsection{Isenção por categoria}

A derrogação por categoria é uma técnica central para as empresas no mercado europeu, uma vez que ela estabelece objetivamente esferas de segurança (sphères de sécurité). A isenção por categoria é aplicada em consonância ao quadro de análise exposto nos regulamentos de isenção. Eles estabelecem presunções de ganhos de eficiência suficientes para compensar um eventual efeito anticoncorrencial. A sua constatação permite, assim, a derrogação da proibição do art. 101.

A modernização desse eixo colocou em questão a aproximação puramente formalista, que foi predominante nos anos 1970, dada a influência da tradição alemã. Os regulamentos de isenção deste período eram catálogos de cláusulas brancas, cinzas e negras. Nesta época, pouco importava a influência das empresas sob a estrutura de mercado, ou seja, mesmo os operadores desprovidos de poder de mercado eram submetidos a um tratamento rígido. Essa metodologia foi duramente criticada, pois eram formulações pouco flexíveis para a dinâmica dos negócios.

A nova aproximação econômica inspirou os regulamentos de isenção de segunda geração. 0 objetivo passou a ser neutralizar o poder de mercado exercido individualmente, sem perder de vista uma aproximação formal, já que as restrições "graves" e "excluídas" são conceitos muito importantes. Destaca-se que o benefício de uma isenção por categoria é subordinado a uma presunção de ausência de poder de mercado e de ausência de restrições graves (PRIETO; BOSCO, 2013, p. 555).

A Comissão Europeia se apoiou no critério das frações em partes de mercado para introduzir uma análise econômica substancial na concessão de isenções coletivas. Para apreender o objeto anticoncorrencial, deve-se recorrer à análise das cláusulas consideradas as "mais nocivas" ou "muito nocivas". Assim, as muito nocivas são consideradas "restrições graves", sendo elas um obstáculo à isenção por categoria. Enquanto as "restrições excluídas" são as menos nocivas e fazem referência às cláusulas contratuais incompativeis com a isenção coletiva, sem incidir na integralidade do contrato, apenas no campo de aplicação do regulamento.

De acordo com Catherine Prieto e David Bosco, essa técnica teve uma grande influência sobre as empresas, apesar de haver um fraco contencioso sobre a matéria. Os autores afirmam que:

Os diretores das grandes empresas têm desde já uma base de trabalho para assegurar suas práticas contratuais. Em contrapartida, os diretores das pequenas e médias empresas deveriam se apropriar desses regulamentos para invocar em sua vantagem as restrições graves ou excluídas. A ordem pública concorrencial coincide recorrentemente com a denúncia de cláusulas de negociações contratuais marcadas por relações de força (PRIETO; BOSCO, 2013, p. 563).

A isenção por categoria tem significativa importância na definição das estratégias de mercado das empresas, permitindo moldar o comportamento das mesmas. Essas zonas de segurança garantem maior previsibilidade na atuação dos órgãos de defesa da concorrência, o que contribui também em maior segurança jurídica para as pequenas e médias empresas. 


\subsection{Isenção individual}

A isenção individual é a última possibilidade de afastar a aplicação do art. 101, §1ํㅡ, do TFUE. Essa derrogação é uma avaliação caso a caso por critérios cumulativos definidos no §3o do dito artigo. É importante frisar que a técnica em questão reforça a abordagem econômica colocada em prática no momento da modernização do Direito da Concorrência da União Europeia.

O regime jurídico da isenção individual foi concebido por uma construção jurisprudencial do Tribunal de Justiça, que estabeleceu os princípios diretores na aplicação do parágrafo 3 o do art. 101, do TFUE, os quais serão explicados a seguir. O primeiro princípio é respeitar a necessidade de qualificação da restrição de concorrência antes de conceder a isenção.

O segundo princípio é a definição que o ônus da prova da violação do parágrafo 1ํ incumbe à Comissão Europeia; e a do parágrafo 3o à empresa, de acordo com o art. 2, do Regulamento (CE) n. 1/2003. Em outras palavras, a Comissão Europeia tem a obrigação de provar a qualificação do acordo, informando a restrição por efeito ou por objeto. Então, a empresa acusada terá a possibilidade sustentar a existência de regulamento de isenção por categoria, o que excluiria a aplicação do art. 101, do TFUE.

No caso de inexistência de regulamento de isenção por categoria, a empresa terá de utilizar a técnica da isenção individual para tentar afastar a aplicação do art. 101, do TFUE. Caberá a esta apresentar provas convincentes para invocar o beneficio da isenção individual. Frisa-se que a inversão do ônus da prova não exime a responsabilidade da Comissão Europeia responder aos argumentos das empresas de maneira convincente.

O terceiro princípio é a delimitação do controle jurisdicional. O Tribunal de Primeira Instância só poderá verificar as regras de procedimento e de motivação, na medida exata da materialidade dos fatos, a não ser nos casos de erro manifesto de apreciação e de desvio de poder.

O quarto princípio é a afirmação implícita da possibilidade de isentar as restrições por objeto. A jurisprudência do Tribunal de Justiça, desde a decisão Grundig, condenou severamente os acordos que visavam ao fechamento dos mercados nacionais. No entanto, com a decisão GlaxoSmithKline, o tribunal afirmou que essa qualificação não será subordinada ao fato de que os consumidores finais sejam privados de vantagens de uma concorrência eficaz em termos de fornecimento ou de preço (TRIBUNAL DE JUSTIÇA DAS COMUNIDADES EUROPEIAS, 2009).

O quinto princípio é a adoção de condições cumulativas do quadro de análise da isenção individual, ou seja, faz-se necessário: (i) a contribuição ao progresso tecnológico e econômico; (ii) a divisão equânime com o consumidor; (iii) a verificação do caráter indispensável da restrição; e (iv) a ausência de eliminação radical de concorrência. O sexto princípio é a possibilidade das partes da decisão de isenção invocar seus direitos contra terceiros.

As orientações da Comissão Europeia recomendam uma ordem a seguir para a apreciação das condições gerais para isenção individual. De início, deve-se realizar o exame dos ganhos de eficiência, ou seja, a identificação de vantagens objetivas sensiveis de natureza a compensar os inconvenientes que resultam para a concorrência. Além disso, a prova das vantagens deve ser positiva, portanto, a afirmação que o acordo em questão não é desfavorável aos consumidores não é suficiente. De acordo com as orientações, os ganhos de eficiência são fatores criadores de valor, podendo ser 
quantitativos ou qualitativos (PRIETO; BOSCO, 2013, p. 539 e s.).

A segunda condição geral de isenção individual é a divisão equânime com o consumidor. Isso pode ser compreendido como uma condição geral, pois o bem-estar do consumidor é a pedra angular da política europeia da concorrência, segundo a Comissão Europeia7. O caso concreto pode revelar uma dificuldade para definir com precisão a repercussão sobre os consumidores. Todavia, é importante frisar que, quanto maior for a incidência de uma restrição à concorrência, maior será a probabilidade de prejuízo aos consumidores a longo termo, visto que a Comissão Europeia considera que a concorrência é muito importante para a inovação a longo termo (COMISSÃO EUROPEIA, 2004, § 92 e s.).

A terceira condição geral é o caráter necessário e proporcional da compensação do efeito negativo sob o consumidor, então:

A Comissão não vai duvidar do juízo comercial das partes, e apenas intervirá quando for razoavelmente evidente que há alternativas realistas e atingiveis. Nesse caso, as partes devem apenas explicar e demonstrar as razões pelas quais eventuais alternativas aparentemente realistas e significativamente menos restritivas ao acordo seriam muito menos eficientes (COMISSÃO EUROPEIA, 2004, § 75).

A quarta condição geral é a ausência de erradicação total da concorrência, que serve para avaliar a possibilidade de impedir a concorrência a longo termo. 0 pretexto de ganhos de eficiência a curto termo por vezes é suscitado para permitir a substancial redução da concorrência, o que não é admitido pela política europeia de concorrência. Para analisar os desdobramentos sob a concorrência a longo termo, deve-se verificar as restrições de capacidade ou de custos de produção que pesarão sob os concorrentes e privilegiar a concorrência nos preços e na inovação.

A análise das etapas da aplicação da regra da razão estruturada do Direito da Concorrência da União Europeia permite de entender um modelo diferente da "rule of reason" do direito estadunidense. A originalidade do modelo europeu coloca em evidência certos aportes importantes para a avaliação dos acordos, especialmente no que diz respeito ao enquadramento dos acordos de cooperação para a inovação.

\section{CONCLUSÃO}

É relativamente comum tratar a regra da razão como um modelo abstrato aplicado em vários ordenamentos jurídicos distintos. Essa simplificação acaba por tratar como homogêneo algo que não é. Apesar das influências entre os modelos, o presente estudo permitiu compreender melhor as complexidades e peculiaridades da regra da razão estruturada no Direito da Concorrência da União Europeia.

7 De acordo com a Comissão, a noção de consumidor no direito da concorrência é mais larga que a do Direito do Consumidor, pois aquela engloba os utilizadores diretos ou indiretos dos produtos ou serviços abrangidos pelo acordo. São incluídos não apenas os consumidores finais, mas também empresas que adquirem produtos para a transformação, por exemplo (COMISSÃO EUROPEIA, 2004, § 84). 
A definição das restrições excluídas e caracterizadas, bem como o diálogo entre as orientações da Comissão e os regulamentos são essenciais para compreender o papel regulador das autoridades europeias da concorrência. Além disso, a perspectiva modernizada da aplicação do Direito da União Europeia nos acordos permite um enquadramento jurídico dos acordos entre as empresas ancorado em uma abordagem fundada nos efeitos econômicos, sem perder de vista a segurança jurídica e a proteção de direitos fundamentais.

Dois aportes do modelo europeu são especialmente relevantes. O primeiro é a repartição do ônus da prova é um elemento central na dinâmica processual e contribui não só para a celeridade do processo, mas também para o reequilíbrio das assimetrias informacionais. O segundo é o enquadramento da cooperação das empresas inovadoras e seus parceiros, por intermédio de normas de Direito da Concorrência. Este último aporte será melhor desenvolvido em estudos futuros, mas a metodologia de aplicação do art. 101, TFUE, explicada no presente artigo, é fundamental para entender como o Direito da União Europeia tem tratado estes acordos específicos.

No que diz respeito à definição da repartição do ônus da prova, entende-se que ela é uma técnica que permite conciliar as assimetrias de informação das autoridades encarregadas da concorrência com a intervenção eficaz desse ramo do Direito. As ditas autoridades têm uma limitação, devido à própria dinâmica de uma economia de mercado, para apreender os detalhes do setor econômico analisado e as condições internas de uma empresa. Em síntese, é possível constatar uma tensão entre o desafio de uma intervenção eficaz, a qual requer maior quantidade de informação de um mercado; e o interesse das empresas de não divulgar suas informações, uma vez que pode ser prejudicial a seus interesses na dinâmica competitiva.

O modelo europeu de repartição de provas, conforme visto, apresenta uma solução em duas etapas para resolver essa tensão descrita. A primeira é de definir a obrigação das autoridades da concorrência para provar a aplicação do art. 101, §1으, do TFUE. A segunda é de impor às empresas o ônus da prova para aplicação das derrogações decorrentes do art. 101, §3으, do TFUE. Em outros termos, as autoridades têm a responsabilidade de demonstrar a restrição de concorrência pelo objeto ou pelo efeito e, em seguida, as empresas têm a obrigação de provar a existência das condições para a isenção por categoria ou individual. Portanto, infere-se que o sentido da modernização do Direito da Concorrência da União Europeia não ficou restrito à dinâmica repressiva, visto que a renovação no domínio dos acordos promoveu um novo enquadramento dos acordos de cooperação.

\section{REFERÊNCIAS}

COMISSÃO EUROPEIA. C 101/54. Comunicação da Comissão sobre a cooperação no âmbito da rede de autoridades de concorrência. 27 abr. 2004. Disponivel em: https://eur-lex.europa.eu/legal-content/ PT/TXT/PDF/?uri=CELEX:52004XC0427(03)\&from=DE. Acesso em: 23 mar. 2020.

COMISSÃO EUROPEIA. C 101. Orientações relativas à aplicação do n. 3 do artigo 81 do Tratado. 27 abr. 2004. Disponivel em: https://eur-lex.europa.eu/legal-content/PT/TXT/?uri=celex\%3A52004XC0427\%2807\%29. Acesso em: 20 abr. 2020.

COMISSÃO EUROPEIA. C 291/1. Comunicação da Comissão relativa aos acordos de pequena importância que não restringem sensivelmente a concorrência nos termos do artigo 101ํ, n. 1, do Tratado 
sobre o Funcionamento da União Europeia (Comunicação de minimis). 30 de ago. 2014. Disponível em: http://eur-lex.europa.eu/legal-content/PT/TXT/PDF/?uri=CELEX:52014XC0830(01)\&from=PT. Acesso em: 20 ago. 2020.

CONSELHO DA UNIÃO EUROPEIA. L 1/1. Regulamento (CE) n. 1/2003 do Conselho de 16 de dezembro de 2002 relativo à execução das regras de concorrência estabelecidas nos artigos 81 e 82 do Tratado. Disponivel em: https://eur-lex.europa.eu/legal-content/PT/TXT/PDF/?uri=CELEX:32003R0001\&from=pt. Acesso em: 14 abr. 2020.

DAUDRET-JOHN, Frédérique; SOUTY, François. Quelle politique de concurrence pour l'Administration Obama?, Concurrences, n. 1, 2009, p. 74-79.

GSTALTER, Jérôme. Droit de la concurrence et droits de propriété intellectuelle: les nouveaux monopoles de la société de l'information. Bruxelas: Bruylant, 2012.

HOVENKAMP, Herbert. The Obama Administration and Section Two of Sherman Act, Boston University Review, v. 90, 2010. Disponivel em: http://scholarship.law.upenn.edu/cgi/viewcontent.cgi?article=2806\&context=faculty_scholarship. Acesso em: 10 jan. 2021.

IDOT, Laurence. L'état des lieux en droit des ententes. In: Propriété intellectuelle et concurrence: pour une (ré) conciliation, Paris, Lexis Nexis, 2012. (Actes du colloque IRPI-AFEC du 8 novembre 2011, Collection de l'IRPI, n. 40)

IDOT, Laurence. Réflexions sur la convergence des droits de la concurrence. Concurrences, n. 4, 2012. JACQUÉ, Jean Paul. Droit institutionnel de l'Union européenne. 8. ed. Paris: Dalloz, 2015.

LEBLOND, Lauren. Pratiques anticoncurrentielles et brevets: études en faveur de la promotion européenne de l'innovation. Bruxelas: Bruylant, 2014.

LEURQUIN, Pablo. Proteção da inovação pelo Direito Brasileiro da Concorrência e diálogo com o Direito da União Europeia. Tese (Doutorado em Direito) - Universidade Federal de Minas Gerais e Université Paris 1 Panthéon-Sorbonne, Belo Horizonte, Paris, 2018.

POLI, Eleonora. Antitrust Institutions and Policies in the Globalising Economy. New York: Palgrave Macmillan: 2015.

POSSAS, Mario Luiz. Concorrência Schumpeteriana. In: KUPFER, David; HASENCLEVER, Lia (orgs.) Economia Industrial: Fundamentos Teóricos e Práticos no Brasil. 2. ed. Rio de Janeiro: Elsevier, 2013.

PRIETO, Catherine; BOSCO, David. Droit européen de la concurrence: ententes et abus de position dominante. Bruxelas: Bruylant, 2013.

RUIZ, Ricardo Machado. Política antitruste e intervenções: algumas reflexões a partir de teorias da firma. In: OLIVEIRA, Amanda Flávio de; RUIZ, Ricardo Machado (orgs.). Remédios Antitruste. São Paulo: Singular, 2011.

SALOP, Steven; SHAPIRO, Carl. Jean Tirole's Nobel Prize in Economics: The Rigorous Foundation of Post-Chicago Antitrust Economics. Antitrust, v. 29, n. 2, 2015. Disponivel em: https://media.crai.com/ sites/default/files/publications/Jean-Tirole-Nobel-Prize-in-Economics-The-Rigorous-Foundationsof-Post-Chicago-Antitrust-Economics-Salop-Shapiro-Antitrust-Magazine-Spring-2015.pdf. Acesso em: 12 dez. 2020. 
TIROLE, Jean. Économie du bien commun. Paris: PUF, 2016.

TIROLE, Jean. Market Failures and Public Policy. Discurso de premiação do Prêmio Nobel de Economia. 8 dez. 2014. Disponivel em: https://www.nobelprize.org/uploads/2018/06/tirole-lecture.pdf. Acesso em: 20 jan. 2021.

TRIBUNAL DE JUSTIÇA DAS COMUNIDADES EUROPEIAS. Processo n. 48-69. Imperial Chemical Industries/Commissão. 14 jul. 1972. Disponivel em: http://eur-lex.europa.eu/legal-content/PT/TXT/PDF/?uri=CELEX:61969CJ0048\&from=FR. Acesso em: 24 abr. 2020.

TRIBUNAL DE JUSTIÇA DAS COMUNIDADES EUROPEIAS. Processo n. 56/64 e 58/64. Établissements Consten SARL e Grundig-Verkaufs-GmbH/Comissão. 13 jul. 1966. Disponivel em: https:/ /eur-lex.europa.eu/legal-content/PT/TXT/PDF/?uri=CELEX:61964CJ0056\&from=EN. Acesso em: 20 ago. 2020.

TRIBUNAL DE JUSTIÇA DAS COMUNIDADES EUROPEIAS. Processo n. 56/65. Société Technique Minière (LTM)/Maschinenbau Ulm GmbH (MBU), 30 jun. 1966. Disponivel em: http://eur-lex.europa.eu/legal-content/PT/TXT/PDF/?uri=CELEX:61965CJ0056\&from=EN. Acesso em: 15 dez. 2020.

TRIBUNAL DE PRIMEIRA INSTÂNCIA DAS COMUNIDADES EUROPEIAS. Processo n. T-112/99, M6 et al./ TF1. 18 set. 2001. Disponivel em: https://curia.europa.eu/juris/showPdf.jsf;jsessionid=9ea7d0f130d6c37614d8abba4585a8d2f490e7d3c60b.e34KaxiLc3eQc40LaxqMbN4Pax0Ne0?text=\&docid=46584\&pagelndex=0\&doclang=PT\&mode=lst\&dir=\&occ=first\&part=1\&cid=510790. Acesso em: 25 nov. 2020.

TRIBUNAL DE JUSTIÇA DAS COMUNIDADES EUROPEIAS. Processo n. C-125/07, C-133/07 P, C-135/07 P e C-137/07 P. Erste Group Bank et al./Comissão. 24 set. 2009. Disponivel em: http://eur-lex.europa.eu/ legal-content/PT/TXT/HTML/?uri=CELEX:62007CJ0125\&from=FR. Acesso em: 24 maio 2020.

TRIBUNAL DE JUSTIÇA DAS COMUNIDADES EUROPEIAS. Processo n. C-135/92. Montecatini/Commission. 8 jul. 1999. Disponivel em: https://eur-lex.europa.eu/legal-content/PT/TXT/PDF/?uri=CELEX:61992CJ0235\&from=EN. Acesso em: 18 dez. 2020.

TRIBUNAL DE JUSTIÇA DAS COMUNIDADES EUROPEIAS. Processo n. C-277/87. Sandoz Prodotti Farmaceuti/Comissão. 11 jan. 1990. Disponivel em: http://eur-lex.europa.eu/legal-content/PT/TXT/PDF/?uri=CELEX:61987CJ0277\&from=FR. Acesso em: 22 abr. 2020.

TRIBUNAL DE JUSTIÇA DAS COMUNIDADES EUROPEIAS. Processo n. 209 a 215/7. Van Landewyck/Comissão. 29 out. 1980. Disponivel em: https://eur-lex.europa.eu/legal-content/FR/TXT/PDF/?uri=CELEX:61978CJ0209\&from=PT. Acesso em: 15 mar. 2020.

TRIBUNAL DE JUSTIÇA DAS COMUNIDADES EUROPEIAS. Processo n. C-519/06. GlaxoSmithKline/Comissão. 6 out. 2009. Disponivel em: https://curia.europa.eu/juris/document/document.jsf?text=\&doci$d=77869 \&$ page Index $=0 \&$ doclang $=P T \&$ mode $=$ Ist $\&$ dir $=\&$ occ $=$ first $\&$ part $=1 \&$ cid $=511056$. Acesso em: 05 jan. 2020.

TRIBUNAL DE JUSTIÇA DA UNIÃO EUROPEIA. Processo n. C-439/09. Pierre Fabre/Présidente de l'Autorité de la concurrence e Ministre de l'Économie, de l'Industrie e de l'Enploi. 13 out. 2011. Disponível em: https://eur-lex.europa.eu/legal-content/PT/TXT/PDF/?uri=CELEX:62009CJ0439_SUM\&from=BG. Acesso em: 20 nov. 2020.

TRIBUNAL DE JUSTIÇA DA UNIÃO EUROPEIA. Processo n. T-11/08. MasterCard/Comissão Europeia, 24 maio 2012. Disponivel em: http://eur-lex.europa.eu/legal-content/PT/TXT/PDF/?uri=CELEX:62008T- 
J0111\&from=PT. Acesso em: 25 abr. 2020.

UNIÃO EUROPEIA. C 202/47. Tratado sobre o Funcionamento da União Europeia. 12 out. 2012. Disponivel em: https://eur-lex.europa.eu/resource.html?uri=cellar:9e8d52e1-2c70-11e6-b497-01aa75ed71a1.0019.01/DOC_3\&format=PDF. Acesso em: 19 nov. 2020.

VESTAGER, Magrethe. Competition: the mother of invention. European Competition and Consumer Day. 18 abril 2016. Disponivel em: https://wayback.archive-it.org/12090/20191130155750/https:// ec.europa.eu/commission/commissioners/2014-2019/vestager/announcements/competition-mother-invention_en. Acesso em: 15 jan. 2021.

VESTAGER, Magrethe. How competition supports innovation. Regulation4Innovation. 24 maio 2016. Disponivel em: https://wayback.archive-it.org/12090/20191130155750/https://ec.europa.eu/commission/commissioners/2014-2019/vestager/announcements/how-competition-supports-innovation_ en. Acesso em: 21 jan. 2021.

VESTAGER, Magrethe. Setting innovation free. Bpifrance Inno Génération. 12 out. 2017. Disponivel em: https://wayback.archive-it.org/12090/20191130155750/https://ec.europa.eu/commission/commissioners/2014-2019/vestager/announcements/setting-innovation-free_en. Acesso em: 11 jan. 2017.

WU, Tim. Taking innovation seriously: antitrust enforcement if innovation mattered most. Antitrust Law Journal, Washington, v. 78, n. 2, 2012. 